\title{
P-0882: Patterns of Glycated Hemoglobin and Microalbuminuria in Patients with Diabetes Mellitus at a Diabetes Clinic in Ethiopia
}

\author{
Bisrat Alem ${ }^{1}$, GetahunTarekegn ${ }^{1}$, Sophia H Wang ${ }^{2}$, Abdurezak Ahmed ${ }^{1}$, Helen Yifter ${ }^{1}$, Tedla Kebede ${ }^{1}$, Yeweyenhareg
} Feleke $^{1}$, Ahmed Reja ${ }^{1}$, Elias S Siraj ${ }^{2}$.

1 Addis Ababa University, Faculty of Medicine, Endocrine Unit, Addis Ababa, Ethiopia

2 Eastern Virginia Medical School, Division of Endocrine \& Metabolic Disorders, Norfolk, VA, USA

\section{Background:}

Glycated hemoglobin ( $\mathrm{HbA} 1 \mathrm{c})$ and microalbuminuria measurements are routinely used in the management of diabetes and its complications in the developed world.

In contrast, in most of sub-Saharan Africa (SSA), management of diabetes is performed using limited laboratory data.

A lot of times, management decisions are made based on a single fasting blood glucose value performed at the day of the visit in the clinic.

Screening for nephropathy is performed by doing routine urinalysis which only detects gross proteinuria and misses a lot of patients with microalbuminuria.

Tests such as $\mathrm{HbA} 1 \mathrm{c}$ and urine microalbumin are not routinely available.

Therefore, there is scant data from Africa regarding the $\mathrm{HbA} 1 \mathrm{c}$ and microalbuminuria pattern in patients with diabetes.

As the prevalence of diabetes and its complications is growing at an alarming rate in SSA, it important that we try to better understand diabetes and its complications urine tests such as $\mathrm{HbA} 1 \mathrm{c}$ and urine microalbumin.

Aim

The aim of this study is to look at and describe the pattern of $\mathrm{HbA1c}$ and microalbumin in patients with diabetes at a specialized diabetes clinic at an academic institution in Ethiopia.

By doing so, the study will determine the proportion of patients who are well controlled and poorly controlled based on internationally accepted $\mathrm{HbA} 1 \mathrm{c}$ criteria

It will also determine the prevalence of microalbuminuria and gross proteinuria.

\section{Method}

This is a retrospective study of 230 patients from the diabetes clinic of Tikur Anbessa Specialized Hospital at Addis Ababa University in Ethiopia.

The HbA1c determination was performed using the A1C Now + Professional kit. The microalbumin level was determined using Microalbumin 2-1 Combo Strip. In addition, a Urinalysis Strip was used to check for proteinuria, among other things. During a period of several weeks in 2016 , the test kits were made available through an international collaboration.

All consecutive patients seen at that time were tested as part of their clinical evaluation. At a later time point, the results were retrieved from medical charts for analysis.

Additionally, data is collected on demographics, clinical characteristics, and other laboratory investigation results.

An approval from the Institutional Ethics review board was obtained for this retrospective study.

Figure 1: Distribution of HbA1c Values by Type of Diabetes

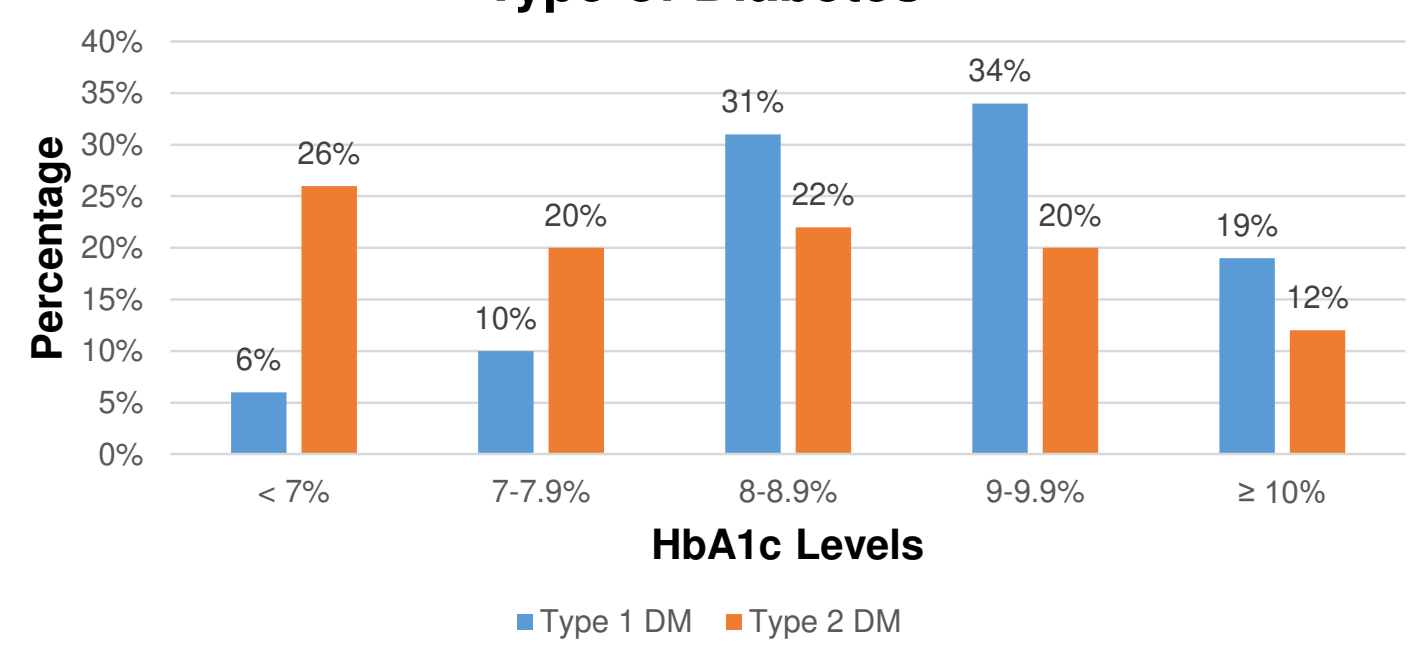

\begin{tabular}{|r|r|r|}
\hline & Type 1 DM & Type 2 DM \\
\hline HbA1c Mean (SD) & $9.2 \%(1.4)$ & $8.2 \%(1.6)$ \\
\hline HbA1c Range & $5.5-13 \%$ & $5.1-13 \%$ \\
\hline
\end{tabular}

Figure 2: Distribution of Fasting Blood Glucose Values by Type of Diabetes

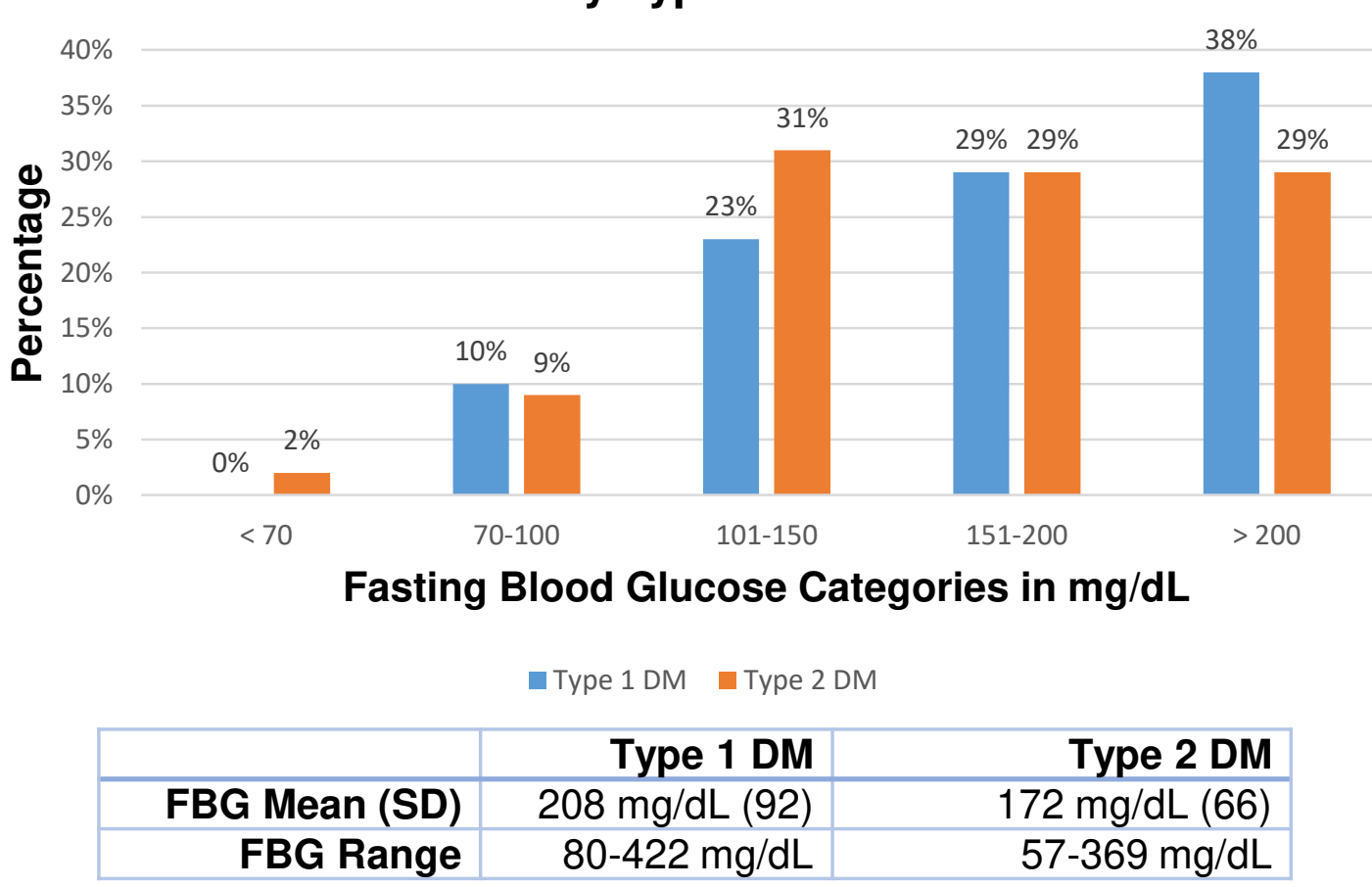

Results

Of the 230 patients who had the tests performed, 125 (54.1\%) were female while $106(45.9 \%)$ were male.

The age range was 18 to 80 years with an average age of $47.1 \mathrm{yrs}$.

The mean $\mathrm{HbA} 1 \mathrm{c}$ value was $8.37 \%$, while the minimum value was $5.1 \%$ and the maximum was $13 \%$

A total of 54 patients (23.3\%) had $\mathrm{HbA1c}$ values $\leq 7 \%, 102(44.2 \%)$ had values $\leq$ $8 \%$, while $38(16.5 \%)$ had values $\geq 10 \%$

On the urinalysis strip test, 125 patients $(54.1 \%)$ were negative for gross proteinuria, 57 patients $(24.7 \%)$ had trace proteinuria, and 48 patients $(20.8 \%)$ had +1 to +4 proteinuria.

On the microalbumin strip test, in 64 patients $(27.8 \%)$, the albumin to creatinine ratio (ACR) results could not be determined due to very low or undetectable urine creatinine.

Of the 166 patients with valid results, 45 (27\%) had ACR of $<30 \mathrm{mg} / \mathrm{g}$ (normal), 108 patients $(65 \%)$ had ACR of $30-300 \mathrm{mg} / \mathrm{g}$ (microalbuminuria), and 13 patients $(8 \%)$ had ACR of $>300 \mathrm{mg} / \mathrm{g}$ (macroalbuminuria).

\section{Discussion \& Conclusions}

Only $23 \%$ of patients with diabetes at the diabetes clinic that we studied are at goal $\mathrm{HbA} 1 \mathrm{c}$ of $\leq 7 \%$ ( $1 \%$ in T1DM and $26 \%$ in Type $2 \mathrm{DM}$ ). In regard to urine tests, $21 \%$ of the diabetes patients have gross proteinuria as measured by urinalysis strip and $8 \%$ as measured by the microalbuminuria strip. An additional $65 \%$ have microalbuminuria most of whom were missed by the urinalysis strip. Those results indicate a significant majority of patients having poor glycemic control and evidence of early nephropathy. We believe that expanding access to $\mathrm{HbA} 1 \mathrm{c}$ and urine microalbumin testing in Ethiopia will provide health care providers and patients the necessary tools for early detection of poor control and complications. Such a measure will translate into improved glycemic control as well as timely management of early nephropathy. That will go a long way in helping control the emerging epidemic of diabetes and its complications in Ethiopia and SSA. Policy makers and public health experts in SSA should look into how best to introduce such tests in a cost effective manner to most diabetes clinics in Africa.

Table 1: Demographic \& Clinical Characteristics of Subjects

\begin{tabular}{|c|c|c|}
\hline & Type 1 DM & Type 2 DM \\
\hline Gender (M/F) & $24 / 28$ & $57 / 53$ \\
\hline \multirow[t]{2}{*}{ Age Mean ( $(\mathrm{SD})$} & $33.67( \pm 10.7)$ & $53.77( \pm 10.6)$ \\
\hline & Range: $18-68$ & Range: $30-60$ \\
\hline \multirow[t]{2}{*}{ BMI Mean $( \pm S D)$} & $22.5( \pm 3.8)$ & $25.9( \pm 4.9)$ \\
\hline & Range: $16-30$ & Range: $17-44$ \\
\hline $\mathrm{BMI}<25$ & $72 \%$ & $45 \%$ \\
\hline BMI 25-30 & $26 \%$ & $34 \%$ \\
\hline $\mathrm{BMI}>\mathbf{3 0}$ & $2 \%$ & $20 \%$ \\
\hline
\end{tabular}

Figure 3: Distribution of Proteinuria Dipstick

Measurement In Patients with Diabetes (Both Type 1 and Type 2)

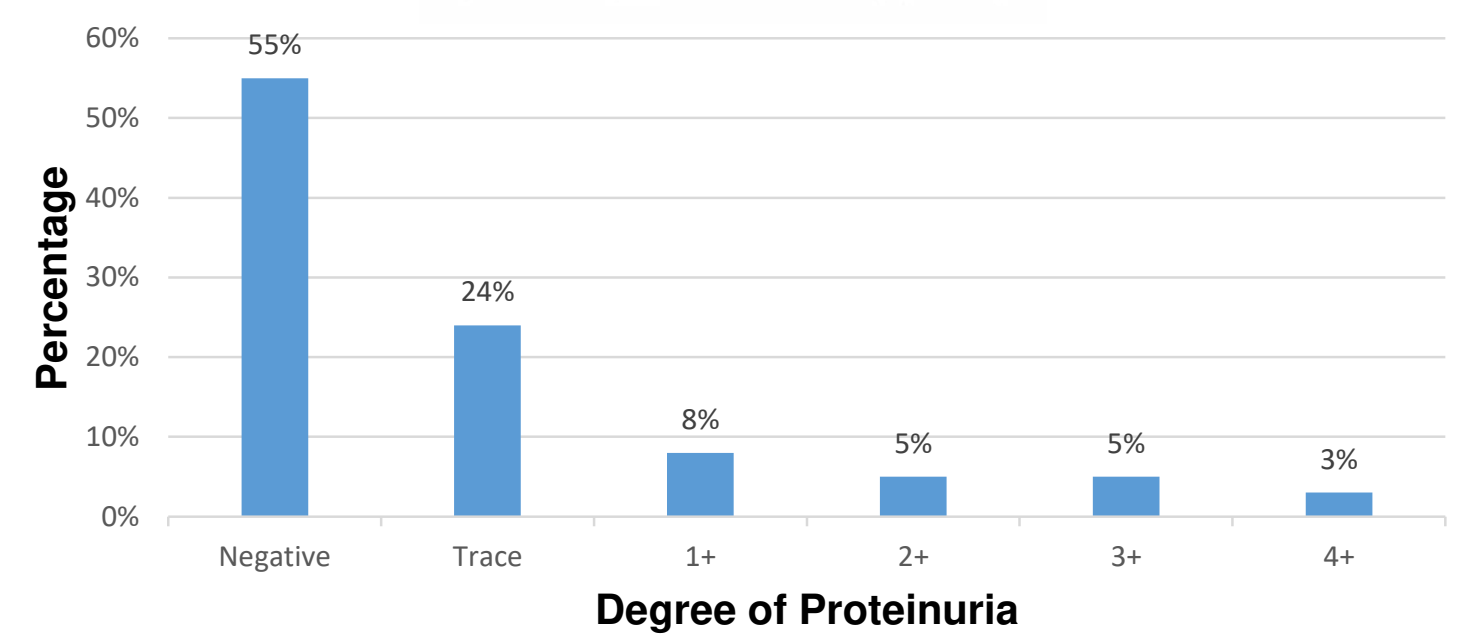

Figure 4: Distribution of Urine Albumin to Creatinine Ratio in Patients with Diabetes (Both Type 1 and Type 2)

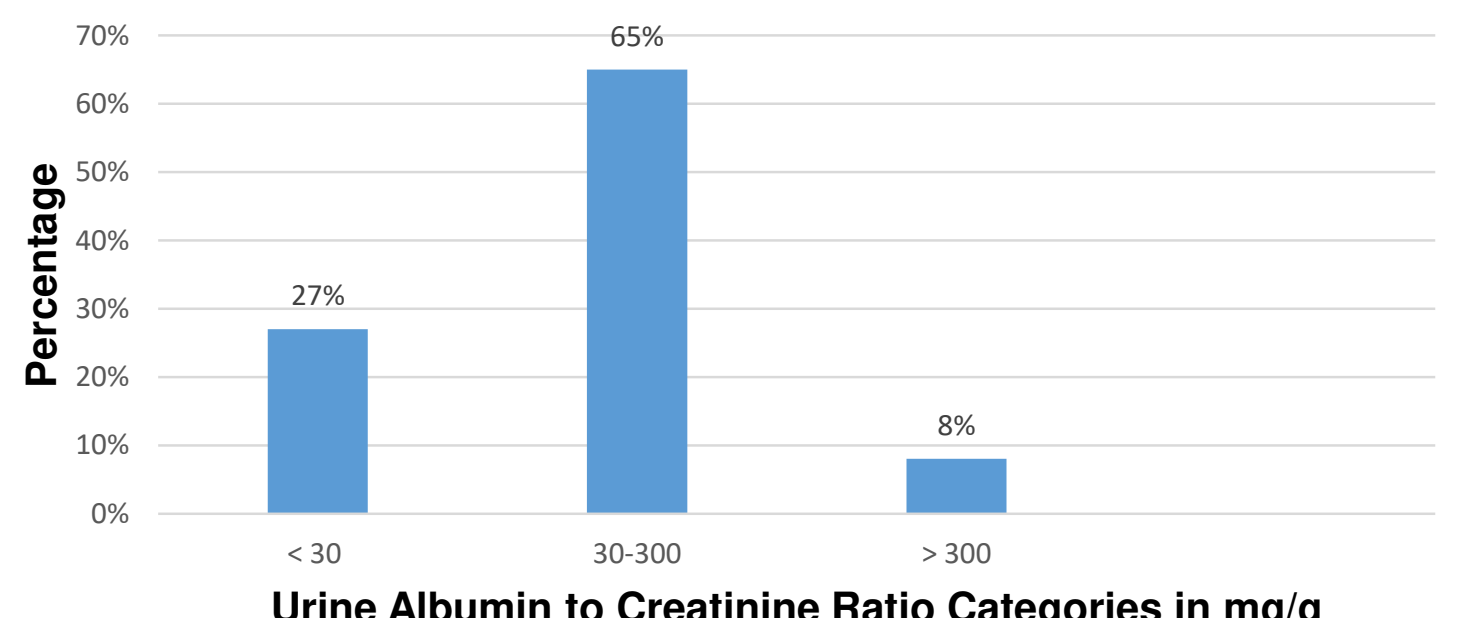

